\title{
Direito à saúde: perspectivas do modelo neodesenvolvimentista brasileiro, privatização da saúde e a questão social
}

\author{
Right to health: perspectives of the model new developmentalism Brazilian, privatization \\ of health and social issue
}

Isabelle Maria Mendes de Araujo *

\begin{abstract}
Resumo:
O objetivo deste trabalho é discutir sobre algumas correntes teóricas que analisam o chamado modelo neodesenvolvimentista brasileiro, apreendendo como é abordada a questão social. Nesse contexto, pretendemos abordar também a questão da saúde e seu processo de privatização, compreendendo a relação público-privada do financiamento da saúde e seus novos modelos de gestão. Para tal, disporemos de revisão crítica literária sobre tais temáticas, apresentando possíveis sínteses para a compreensão do quadro atual de saúde brasileira. Desse modo, tratar a saúde como direito nas sociedades capitalistas é uma tarefa que envolve diversos atores, contudo, envolve também o que historicamente foi construído em torno da apropriação privada da saúde e seus setores dominantes. Constatamos a transferência de recursos públicos para o incentivo do setor privado da saúde no pré e pós-SUS, além da transferência, nos últimos anos, da administração pública ao setor privado. Observamos que a herança neoliberal da década de 1990 criou as bases para o atual modelo de econômico, atingindo de forma compensatória e limitada as classes populares, como também as raízes da seguridade social, na qual a saúde é uma das faces atingidas pelas contradições do sistema, sendo ferido, pois, o direito à saúde.
\end{abstract}

Palavras-chave: Modelo econômico. Financiamento público. Gestão. SUS.

\begin{abstract}
:
The objective of this work is to discuss some current theories that analyze the model called new developmentalism brazilian, highlighting how the social issue is studied. In this context, we intend to also study the issue of health and its privatization process, including the public-private health financing and its new management models. To this end, we will have theoretical review on these themes, presenting the critical perspective, possible synthesis to understand the current situation of brazilian health. Treating health as a right in capitalist societies is a task that involves many actors, however, also involves what historically was built around the private ownership of health and its leading sectors. We note the transfer of public funds to encourage private sector health before and after SUS, and the transfer, in recent years, the public administration to the private sector. We observed that the neoliberal legacy of the $90 \mathrm{~s}$ laid the foundations for the current economic model, reaching a compensatory way
\end{abstract}

- Sanitarista, Mestre em Saúde Coletiva (UFPE) e Doutoranda em Saúde Coletiva (UFRN). E-mail: isabellesaudelivre@hotmail.com 
and limited to the lower classes, as well as the roots of social security, in which health is one of the faces affected by the contradictions of the system, being injured as the right to health.

Keywords: Economic model. Public funding. Management. SUS.

\section{Introdução}

Ao considerar o contexto atual em que o Brasil se encontra, como uma das maiores economias mundiais, sob o fulcro do Novo-desenvolvimentismo, e que, todavia, continua mantendo restrições de gastos para o sistema de seguridade social, com repercussões na saúde pública, o presente artigo pretende trazer algumas reflexões acerca desse cenário, evidenciando o debate em torno do (neo)desenvolvimentismo enquanto modelo econômico do país.

Como mediação para este debate, instiga-nos a discussão de diferentes correntes teóricas na perspectiva da caracterização, bem como a compreensão da "questão social" presente no discurso dos chamados neodesenvolvimentistas.

Além da dimensão estrutural econômica, pretendemos discutir o campo da saúde, apreendendo-a enquanto direito social e seu histórico processo de privatização no contexto pré e pós-implementação do Sistema Único de Saúde - SUS. Para tal, faremos uma revisão crítica sobre a relação público-privada do financiamento da saúde, observando o papel do Estado, o desenvolvimento das empresas privadas em saúde, o repasse de recursos públicos para o setor privado e a dimensão da terceirização da administração pública, historicizando a apropriação privada da saúde no Brasil.

Como veremos, o debate do neodesenvolvimentismo não nos permite negar traços ainda prevalecentes da dependência analítica da formação social brasileira, apesar das mudanças em curso em sua historicidade. A exploração dos trabalhadores se dá tanto pela apropriação do mais valor como pela via do consumo, pois "geram-se enormes contingentes de populações disponíveis, conservadas como força de reserva, em condições subumanas, mas dependentes do mercado para a sua subsistência" (FONTES, 2010, p. 204).

A forte retomada do chamado neodesenvolvimentismo que assistimos nos últimos governos brasileiros tem como tendência a imagem do desenvolvimento como parte de um contínuo "progresso", capaz de superar as mazelas do processo irreversível de 
produção capitalista. Todavia, alerta Mota (2010), na América Latina, de modo geral, o desenvolvimento dessa etapa do capitalismo se deparou com condições históricas particulares, principalmente no que diz respeito aos projetos de governantes que, durante as eleições realizadas nos anos 1990, construíram discursos que tinham como pilares fundamentais o crescimento econômico com desenvolvimento social.

Não obstante tal programática, os países da região não puderam fugir do movimento de internacionalização da economia, incorporando-se à dinâmica mais geral dos processos especulativos, à manutenção da exploração do trabalho pelo capital, com expressivos reflexos na questão social dos países.

\section{O modelo de desenvolvimento econômico brasileiro e a questão social}

Segundo Atílio Boron (2007), o desenvolvimento do capitalismo possui caráter histórico, envolvendo o papel de diferentes agentes, a inserção de países em um mercado mundial marcado por profundas assimetrias, e a centralidade na problemática política e estatal.

Nessa perspectiva, para compreendermos o atual modelo econômico brasileiro há de se visitar correntes teóricas econômicas, tanto no campo conservador ortodoxo como no campo heterodoxo. No campo conservador, encontramos a visão da ortodoxia econômica (neoliberal) que, de acordo com Santos (2007), abarcam três grandes linhas argumentativas: (1) que o crescimento econômico, por si próprio, não trará a redução das desigualdades; (2) que os gastos sociais no Brasil não são baixos, pelo contrário: o que é preciso fazer é torná-los mais eficientes, melhorando a alocação de recursos e focalizandoos nos segmentos mais atingidos pela pobreza; (3) propostas de desenvolvimento baseadas no investimento do "capital humano", reformas tributárias, previdenciárias e trabalhistas, programas de microcrédito etc. Em relação ao pensamento econômico heterodoxo, por sua vez, ensaia-se os primeiros passos de uma contraofensiva ideológica, apostando na crise do neoliberalismo na América Latina. Tendo, desse modo, a gradual retomada de temas como o desenvolvimento econômico e a equidade social.

De acordo com Santos (2007), no campo heterodoxo, emerge o novo desenvolvimentismo, que seria uma corrente contemporânea do pensamento econômico nacional nascida em meados da década de 1950, gestada na Comissão Econômica para a 
América Latina e Caribe (CEPAL) e no Instituto Superior de Estudos Brasileiros (ISEB). Os quais começaram um processo intelectual de formulação teórica sobre as condições estruturais do subdesenvolvimento periférico, com ênfase nas especificidades da América Latina. Até aproximadamente 1960, o chamado nacional-desenvolvimentismo gozou de enorme prestígio intelectual e político na América Latina, sendo considerado o pensamento hegemônico à época, destacando-se os pensadores como Ignácio Rangel, Celso Furtado e Helio Jaguaribe (BIELSCHOWSKY, 1988). O modelo de desenvolvimento preconizado pelos desenvolvimentistas, baseado fundamentalmente na industrialização, não alcançou, no entanto, os resultados esperados em termos, por exemplo, da autonomia nacional e da modernização dos setores econômicos e sociais mais atrasados da região.

Para Santos (2007), esse quadro referente à hegemonia do nacionaldesenvolvimentismo e do relativo otimismo quanto às possibilidades de autodeterminação dos povos e nações da periferia desaparece, nos anos 1980, com o neoliberalismo. Essa estratégia ideológica-política das classes dominantes, endereçada aos movimentos operários dos países centrais, ao comunismo do Leste Europeu e aos movimentos de libertação nacional do Terceiro Mundo, atingiu indiscriminadamente a todos, e o debate sobre desenvolvimento econômico e social saiu de cena para dar lugar à agenda política neoconservadora na perspectiva da liberalização dos mercados, estabilidade dos preços e privatização dos bens públicos. O cenário brasileiro dos anos 1990 evidencia claramente a política econômica neoliberal, privatizante, nos governos de Collor e de Fernando Henrique Cardoso.

Recentemente, diferentes autores estão conceituando a atual política econômica brasileira, dentre as expressões usadas, de o "novo-desenvolvimentismo", "neodesenvolvimentismo" (SISCÚ; PAULA; MICHEL, 2007). Para Siscú, Paula e Michel (2007) e Santos (2007), o principal objetivo dos novo-desenvolvimentistas seria delinear um projeto nacional de crescimento e desenvolvimento econômico combinado a uma melhora substancial nos padrões distributivos do Brasil. A consecução desse objetivo passaria, necessariamente, por um determinado padrão de intervenção do Estado na economia e na "questão social", principalmente no tocante à redução da pobreza inerente às economias capitalistas. 
Já para o economista Bresser-Pereira (2006), o novo-desenvolvimentismo seria, ao mesmo tempo um "terceiro discurso", entre o discurso populista e o da ortodoxia convencional (neoliberal), e o conjunto de diagnósticos e ideias para a formulação, por cada Estado-Nação, da sua estratégia nacional de desenvolvimento. Seria, assim, um conjunto de propostas de reformas institucionais e de políticas econômicas, por meio das quais as nações de desenvolvimento médio buscariam, no início do século XXI, alcançar os países desenvolvidos. Para o autor, o antigo desenvolvimentismo não é uma teoria econômica que se baseia principalmente na macroeconomia keynesiana e na teoria econômica do desenvolvimento, mas é uma estratégia nacional de desenvolvimento.

É a maneira pela qual países como o Brasil podem competir, com êxito, com países ricos e, gradualmente, alcançá-los. É o conjunto de ideias que permite às nações em desenvolvimento rejeitar as propostas e pressões dos países ricos de reforma e de política econômica, como a abertura total da conta capital e o crescimento com poupança externa, na medida em que essas propostas representam a tentativa de neutralização neoimperialista de seu desenvolvimento. É a forma por meio da qual empresários, técnicos do governo, trabalhadores e intelectuais podem se constituir em nação real para promover o desenvolvimento econômico (BRESSER-PEREIRA, 2006).

Desse modo, o tripé novo-desenvolvimentista, para Bresser-Perreira (2006), para um país se desenvolver aproveitando as forças do mercado, seria: (1) manter a estabilidade macroeconômica; (2) contar com instituições gerais que fortaleçam o Estado e o mercado e com um conjunto de políticas econômicas que constituam uma estratégia nacional de desenvolvimento; e (3) promover a poupança interna, o investimento e a inovação empresarial.

Ora, o que o autor caracteriza não seria o amadurecimento do capitalismo no Brasil? Expressando sua formação social capitalista, desenvolvida, perfeitamente integrada ao capitalismo internacional?

Embora a concepção novo-desenvolvimentista aborde a intervenção estatal na "questão social", concretamente, sua dimensão político-econômica caracteriza-se enquanto uma roupagem do mesmo capitalismo histórico do país, ao aprofundar a relação capital-trabalho de exploração. Nos alerta Santos (2007) que o tipo de combate à exclusão social proposto passaria necessariamente pelo crescimento econômico a taxas acima de 
$5 \%$, ou seja, a tese é de que o crescimento econômico é o principal fator para a redução das desigualdades sociais. O principal meio para a redução das desigualdades sociais, dizem os novo-desenvolvimentistas, são as políticas econômicas de corte keynesiano - controle de capital, expansão do gasto público, câmbio fixo e redução das taxas de juro - e a promoção da equidade social, entendida como igualdade de oportunidades (SANTOS, 2007).

Todavia, na configuração atual da questão social brasileira não houve nenhuma regressão estrutural na modalidade de exploração do trabalho imperante no país.

Em Bresser-Pereira (2006), encontramos que o desenvolvimento é um processo de acumulação de capital e de incorporação de progresso técnico por meio do qual a renda por habitante ou, mais precisamente, os padrões de vida da população aumentem de forma sustentada.

\begin{abstract}
É de acordo com essa orientação que os governos, em todos os níveis (federal, estadual e municipal), criam mecanismos de crédito para os muito pobres investirem em pequenas empresas, constroem casas populares subsidiadas, investem em gastos sociais nas periferias das grandes cidades. Ou quando o governo federal, respondendo à pressão dos movimentos sociais, promove a reforma agrária, ainda que a justificativa econômica capitalista para os gastos correspondentes não seja clara. Quando os muito pobres se tornam pequenos empresários, seja porque obtiveram crédito, seja porque receberam um pedaço de terra, eles estão aos poucos se inserindo no mercado capitalista. Por outro lado, todos os gastos sociais com os pobres, principalmente os de educação e saúde, estão também melhorando a qualidade de vida do setor informal e, dessa forma, integrando-o ao moderno e superando a dualidade, não pela absorção do tradicional pelo moderno, mas pela melhoria das condições de vida dos pobres. O desenvolvimento só é possível com a integração da população pobre no processo (BRESSER-PEREIRA, 2006, p. 45).
\end{abstract}

Como podemos perceber, há a incorporação de "aspectos sociais" ao conceito do "desenvolvimento". Como sistematiza Santos (2007), a ideia dos novo-desenvolvimentistas em mesclar crescimento econômico e equidade social não é nenhuma novidade. $O$ debate arrasta-se por três décadas, e quando chega ao século XXI as suas formulações experimentam um grave retrocesso, pois não há um debate sobre a natureza e as funções do Estado no modo de produção capitalista, e nem uma avaliação da fusão dos interesses das classes dominantes em torno do capital financeiro e da financeirização da riqueza e dos constrangimentos do mercado mundial à formação de um capitalismo autônomo. 
Dessa forma, concordamos com Santos (2007) ao indagar sobre o que significa, em termos políticos e ideológicos, a integração dos "aspectos sociais" - via o conceito de equidade social, herdado da tradição liberal clássica e que aparece nos principais relatórios das agências multilaterais neoliberais - ao debate do neodesenvolvimentismo.

O reformismo social keynesiano, um dos pilares fundantes do projeto novodesenvolvimentista, assenta-se na tese de que "a redistribuição [da renda e da riqueza] representa uma parte secundária em sua filosofia social, e, assim mesmo, somente como parte do mecanismo da estabilização da macroeconomia, e não como um meio para um objetivo ideal como a igualdade" (SKIDELSKY, 1999, p. 78).

Ora, a incorporação dos valores da justiça social ocorre não como um fim em si mesmo, mas para legitimar ações de técnicos do planejamento econômico. Os "aspectos sociais", quando figuram em projetos heterodoxos de desenvolvimento, figuram em termos secundários, adjetivos, uma espécie de retórica da consciência moral e ética dos formuladores da política econômica, que ora propõem intervenções na "questão social" para neutralizar opositores, à direita e à esquerda, ora para pacificar tensões sociais (SANTOS, 2011). Em última instância, trata-se de luta pela manutenção da ordem econômica e da coesão social, e não de transformações estruturais visando à superação do modo de produção capitalista, eternizado e naturalizado como o sistema social capitalístico possível.

Alertam alguns autores, como Paulo Netto (1992), que tomar a "questão social" concretamente é apreendê-la como problemática configuradora de uma totalidade processual específica, é remetê-la à relação capital/trabalho - o que significa, liminarmente, colocar em xeque a ordem capitalista. A política social deve, pois, necessariamente constituir-se em políticas sociais: recortadas como problemáticas particulares e, assim, enfrentadas.

\section{Saúde: direito ou mercadoria?}

Ao apreender o modelo econômico capitalista brasileiro, base estrutural que historicamente molda sua supraestrutura: relações sociais, jurídicas, políticas, enfim, iremos percorrer os caminhos do setor saúde no Brasil, abordando-o como direito legitimado na Constituição de 1988, assim como seus dilemas na relação do financiamento 
público-privado no pré e pós-Sistema Único de Saúde - SUS e seu processo de privatização atual.

Na Constituição Brasileira de 1988, encontramos que saúde é direito de todos e dever do Estado e que devem ser garantidos: "condições de alimentação, habitação, educação, renda, meio ambiente, transporte, emprego, lazer, liberdade, acesso e posse da terra e acesso a serviços de saúde" (BRASIL, 1988). Nessa dimensão, Paim (2007) elucida que a saúde pode ser entendida como um produto das condições objetivas da existência humana, dependente das condições de vida e das relações que os homens estabelecem entre si e com a natureza por meio do seu trabalho. De modo que promover saúde é conhecer como se apresentam as condições de vida e de trabalho do povo na sociedade, para que seja possível intervir socialmente na sua modificação, enquanto respeitar o direito à Saúde supõe mudanças na organização econômica (estrutura social), determinante das condições precárias de vida e trabalho insalubres, e na estrutura jurídicapolítica perpetuadora de desigualdades na distribuição de bens e serviços.

Ora, há quase 25 anos pós Constituição, indagamos-nos se, de acordo com o que Paim elucida a respeito do direto à saúde, galgamos modificações pertinentes à estrutura, à política e à jurisdição da saúde, efetivando o idealizado pelo movimento sanitário dos anos 1980 ? Percorramos a história da saúde brasileira.

É inegável que o processo de implementação do SUS, ainda em andamento, possibilitou a garantia universal da assistência à saúde à população brasileira, com relevante ampliação de ações e serviços ofertados, avançando em modelos de atenção à saúde, na organicidade do sistema sanitário, na participação social etc. Contudo, a obtenção de uma rede de cuidados equânimes e integrais permanece como um propósito a ser alcançado.

Ao percorrer o pré-SUS, no livro Saúde e Previdência: estudos de política social (1981), Braga e Paula analisam criticamente o modelo de saúde brasileiro, desde os anos 1950 até fins de 1970, enfocando a formação do complexo médico-assistencial-privatista e a questão do financiamento da saúde relacionado à Previdência Social. É nesse período em que há a apropriação privada da saúde. Antes do SUS, a assistência à saúde fora majoritariamente financiada pela Previdência Social por meio do Instituto Nacional de Assistência Medica e Previdência Social - INAMPS, de modo que apenas os trabalhadores 
contribuintes da Previdência tinham acesso à assistência, menos de $20 \%$ da população. A política de financiamento da saúde consistia em repassar, a partir de contratos, os recursos do INAMPS e da União ao setor privado para a prestação de serviços assistenciais. É nesse momento em que há o boom expansionista do setor privado pelo incentivo do Poder público, que, ao invés de financiar a construção de serviços de saúde próprios estatais públicos, priorizava a celebração de contratos com o setor privado para este fim.

Em relação ao nascedouro das empresas privadas no Brasil, suas atividades surgem à margem do planejamento governamental, mas bastante integrada à rápida expansão da economia e aos desígnios das empresas empregadoras como locci de operação dos benefícios previdenciários. De acordo com Ligia Bahia (2008), as condições favoráveis à expansão das empresas especializadas na comercialização de planos privados de saúde se relacionaram ao crescimento econômico brasileiro nos anos 1960 e 1970.

Além de inaugurar políticas estruturadas de incentivo à demanda por serviços, o período pré-SUS nos anos 1970 também foi marcado pelo pioneirismo das políticas governamentais de apoio à oferta privada de estabelecimentos de saúde. Exemplo disso foi a criação, durante o governo Geisel, do Fundo de Apoio ao Desenvolvimento Social (FAS), composto de linhas de crédito para obras na área social, como hospitais, que alavancaram reformas e construções de estabelecimentos hospitalares privados, vinculados a empresas privadas de planos privados de saúde (BAHIA, 2008).

Entretanto, a partir dos anos 1980, com as recorrentes denúncias de fraude dos serviços de saúde da Previdência Social e o contexto do acirramento da anunciada crise financeira previdenciária em relação à intervenção estatal, que antes havia sido decisiva para imprimir uma acelerada privatização do sistema de saúde brasileiro, o Estado assume formalmente, nesse momento, a direção do fortalecimento do segmento público e filantrópico (SANTOS, 2009).

O processo de democratização, tempos de retração econômica e ajuste fiscal, não favoreceu a redução das políticas de discriminação e privilégios na saúde, ao contrário, propiciou a inclusão seletiva de novos segmentos ao consumo de bens e serviços, como os planos e seguros privados de saúde, sobre os quais discorreremos a seguir.

Em 1987, pelo menos 15\% da população brasileira estavam vinculadas a coberturas de planos privados de saúde. Mas, de acordo com Ligia Bahia (2008), ainda era incipiente 
o conhecimento sobre a origem das novas demandas, a magnitude das despesas envolvidas com o financiamento desses planos de saúde e o aporte de recursos públicos para custeálos. Essa constatação, todavia, não desautoriza as inferências sobre a preservação do traço empresarial/coletivo das novas clientelas de planos privados de saúde. Embora, em meados da década de 1980, a comercialização dos planos individuais tenha adquirido mais fôlego, as explicações mais sistêmicas sobre o crescimento do mercado de planos de saúde não eram encontradas nos movimentos isolados dos indivíduos em 'fuga do SUS' e sim, provavelmente, nas mudanças nos processos de negociação salarial.

Em tempos de estagnação econômica, redução do número de postos formais de trabalho, decréscimo dos valores diretos dos salários; o valor dos planos privados de saúde é ressignificado. Como integrantes da cesta de benefícios indiretos e não tributáveis dos contratos de trabalho, os planos de saúde tornaram-se moeda de troca salarial, fortalecendo a segmentação (publico $x$ privado) do sistema de saúde brasileiro que se pretendia superar com a criação do SUS (BAHIA, 2008).

Desse modo, as contraditórias políticas governamentais que trataram das relações entre o público e o privado, tecidas em meio à recessão econômica e ao subfinanciamento da saúde, não permitiram que o 'principal objetivo' para a construção do SUS definido na 8 a Conferencia Nacional de Saúde de 1986 - a expansão e o fortalecimento do setor estatal - fosse integralmente cumprido.

Embora tenha havido o fortalecimento do setor público estatal da saúde com o fortalecimento do SUS, nem os prestadores privados de serviços passaram a ser controlados sendo coibidos seus lucros abusivos, e nem muito menos foi considerada a possibilidade de expropriação dos estabelecimentos privados nos casos de inobservância das normas estabelecidas pelo setor estatal (BAHIA, 2008; SANTOS, 2009).

Ao tomar como referência a produção de serviços e os gastos públicos realizados no pré-SUS e pós-SUS, observa-se um movimento contraditório: o notável aumento da quantidade de atividades assistenciais pelos prestadores de serviços públicos e estatais, principalmente os ambulatoriais municipais e a relativa estabilidade no volume de transferências de recursos financeiros governamentais para o privado-público, assim nomeado o setor privado que recebe recursos do Estado para prestar ou gerir serviços (GERSCHMAN, 2008). Com a progressiva construção de serviços próprios do SUS, o volume 
das contratualizações com o setor privado deveria ter diminuído, entretanto, a realidade dos municípios e dos estados evidencia a manutenção da relação público-privada consubstanciada nos contratos de serviços, principalmente, nas áreas laboratoriais e de diagnóstico.

A composição dos fundos públicos para determinadas especialidades e equipamentos variou segundo o gradiente de uso universal ou não no pós-SUS. No polo público próprio situaram a imunização e a internação domiciliar (cerca de 95\% e 83\% respectivamente); na zona privado-pública predominou a hemodiálise (82,5\%), a radioterapia (55\%) e a medicina nuclear (50\%); e no polo constituído pela parcela destinada exclusivamente a demandas privadas (planos e seguros de saúde privado), destacaram-se a ressonância nuclear magnética (56\%), a radiologia odontológica (cerca de 55\%) e a cirurgia oftalmológica a laser (52\%) (BAHIA, 2008).

As informações dos cadastros de estabelecimentos evidenciam que os hospitais privados abrigam a maior parte dos serviços de alta complexidade como quimioterapia, centro de tratamento intensivo, cirurgia cardíaca e até unidades de emergência. Constatase o predomínio privado, quer como forma de propriedade, quer na destinação do serviço/equipamento, em diversas áreas assistenciais, inclusive nas prioritárias para o Ministério da Saúde, como a da detecção precoce de neoplasia (em 2005, apenas 15\% dos mamógrafos eram públicos e cerca de $50 \%$ dos demais aparelhos destinavam-se, exclusivamente, ao atendimento não universal) (BAHIA, 2008).

Essa nova geometria público-privada continuou a abrigar arranjos assistenciais com base no predomínio do privado-público. O perfil privado-público de determinadas especialidades e procedimentos, categorizados como de alto custo, não foi modificado, ao contrário, em certos casos se acentuou na história da saúde do país. Os prestadores privado-públicos permaneceram controlando a produção de procedimentos de hemodiálise (pelo menos 93\% em 1987 e 94,5\% em 2007); radioterapia (pelo menos 89,5\% em 1987 e 86\% em 2007); medicina nuclear (pelo menos 50\% em 1987 e 76,5\% em 2007) e quimioterapia (pelo menos 63\% em 1987 e 72,3\% em 2007). Essa tendência estendeu-se também à produção de tomografias computadorizadas (3\% em 1987 e 43\% em 2007) e hemoterapias (40\% em 1987 e 65\% em 2007) (BAHIA, 2008). 
A partir dos dados, constatamos que mesmo depois da implementação do Sistema Único de Saúde, a saúde, o fundo público de saúde, continuou a assumir o caráter de propriedade privada, como no pré-SUS. Ou seja, por meio dos setores privados dominantes da saúde, o fundo público foi/é apropriado para acumulação e reprodução do capital (OLIVEIRA, 1998), hoje na fase da financeirização.

Nesse sentido, faz-se necessário e imperativo analisar as tensões em torno da saúde no campo da questão social, visto que historicamente o capital vem penetrando e expropriando esse setor do país.

Segundo Santos (2009), a expansão do setor privado no Brasil se deve, principalmente, às desonerações fiscais a prestadores privados e consumidores dos seus serviços; ao gasto de órgãos públicos com prestadores privados para a assistência à saúde de seus trabalhadores e familiares; e pela a duplicidade de uso de serviços do SUS por segurados de planos e seguros de saúde, quando não ocorre o ressarcimento pelas operadoras ao sistema público.

Em nome da desoneração do SUS, pelo menos 10 bilhões de recursos públicos/sociais foram revertidos em 2006 para o mercado de planos e seguros e estabelecimentos privados de saúde. Como bem elucida Ligia Bahia (2008), em nome da desoneração do SUS, as empresas estatais e os órgãos da administração direta financiam planos e seguros privados de saúde para seus trabalhadores.

Tudo indica que as motivações que inspiraram a política de universalização dos planos privados de saúde para os servidores civis da União, isto é, a extensão de subsídios financeiros para funcionários da administração federal direta e seus dependentes, não estivessem afeitas às mudanças no modelo assistencial. Pelo contrário, a extensão e legitimação de uma política de transferência de recursos públicos orçamentários é, explicitamente, contrária aos preceitos constitucionais, que vedam o repasse de recursos públicos para o setor privado; além disso, visou responder, com a ampliação de benefícios indiretos, às demandas salariais. Os planos privados de saúde saíram mais em conta do que as pressões por aumento salarial, trazendo ganhos de produtividade às empresas empregadoras e de representatividade para as associações sindicais (BAHIA, 2008). 
Ou seja, a saúde como um bem de consumo é comprada pelos setores privados a fim de ser garantido o acesso assistencial aos trabalhadores, perspectiva de acesso a Direitos bem eficaz para o modelo neodesenvolvimentista.

Em síntese, ao longo dos vinte anos de implementação do SUS, as políticas públicas de apoio às empresas de planos e seguros de saúde e estabelecimentos assistenciais foram intensificadas e diversificadas em nome do direito universal à saúde. Como observamos, a construção dos pilares de apoio à privatização da assistência à saúde é complexa e antiga, precede o SUS e se entranha na arquitetura das relações contemporâneas entre o setor público e o privado.

Além dessa dimensão privatizante a partir do repasse de fundos públicos ao setor privado de serviços e estabelecimentos, do incentivo ao crescimento das empresas privadas, dos planos e seguros privados, de servir como moeda de troca salarial; esboçaremos outra dimensão privatizante da saúde, a saber, a terceirização da administração do setor público, gestão delegada ao setor privado, sistematizada como novos modelos de gestão dos serviços públicos.

Esse fenômeno é verificado a partir dos anos 1990, nos governos neoliberais, prolongando-se até os dias atuais (governos neodesenvolvimentistas, ou, como registra Santos (2011), social-liberais. No governo de FHC é encaminhado ao Congresso Nacional, 1995, o Plano da Reforma do Estado, o qual parte do princípio de que as Funções do Estado deveriam ser de coordenar e financiar as políticas públicas e não de executá-las. Defendia que "nem tudo que é público é estatal" e afirmava que "devemos socializar com a iniciativa privada a responsabilidade de diminuir as mazelas provocadas pelo mercado" (REZENDE, 2008, p. 56). Avaliava, ainda, que "se o Estado não deixar de ser produtor de serviços, ainda que na área de políticas públicas sociais, para ser agente estimulador, coordenador e financiador, ele não irá recuperar a poupança pública." Àquele modelo de gestão do Estado, chamou de "administração gerenciada" (REZENDE, 2008, p. 59).

É consenso no campo teórico da saúde coletiva que a Política de Administração Pública é um instrumento fundamental para a Gestão do SUS. Desse modo, dependendo de como o governo pretende administrá-la, os equipamentos e trabalhadores públicos, haverá sempre repercussões pró ou contra a universalização e a integralidade das Políticas Públicas de um modo geral, principalmente para a Saúde, porque o SUS foi instituído não 
apenas como um novo modelo de atenção à saúde, mas enquanto um modelo de gestão do Estado, federalizado, descentralizado, com comando único em cada esfera de governo e com pactuação da política entre essas, com financiamento tripartite, com participação da comunidade e com controle social, dentre outras dimensões (BRAVO et al., 2008).

No contexto supracitado, as Organizações Sociais (OSs) foram concebidas no Brasil como instrumento de viabilização e implementação de políticas públicas, conforme o Plano Diretor da Reforma do Aparelho do Estado. De acordo com Rezende (2008), em 1997, o governo estabeleceu critérios para definir, sob a denominação de Organizações Sociais (OSs), as entidades que, uma vez autorizadas, estariam aptas a serem "parceiras do Estado", na condução da "coisa pública". Aprovou-se no Congresso Nacional a Lei n.o 9.637, em 1998, que "dispõe sobre a qualificação de entidades como organizações sociais, a criação do Programa Nacional de Publicização, a extinção dos órgãos e entidades que menciona e a absorção de suas atividades por organizações sociais".

As OSs podem, assim, contratar funcionários sem concurso público, adquirir bens e serviços sem processo licitatório e não prestar contas a órgãos de controle internos e externos da administração pública, porque são consideradas "atribuições privativas do Conselho de Administração", que podem todo o mais, tal como:

[...] aprovar por maioria, no mínimo, de dois terços de seus membros, o regulamento próprio contendo os procedimentos que deve adotar para a contratação de obras, serviços, compras e alienações e o plano de cargos, salários e benefícios dos empregados da entidade (BRASIL, 1998).

Após a lei da criação das OSs, foi criada, na mesma perspectiva, a Lei da Organização da Sociedade Civil de Interesse Público - OSCIP, a partir da qual grande parte das ações de governo pode ser transferida ao setor privado, exceto as do chamado Núcleo Estratégico e Burocrático, que permanecem com o Estado.

Sobre a inconstitucionalidade e a ilegalidade de tal terceirização, faz-se necessário lembrar que a Constituição Federal, em seu art. 196, estabelece que a saúde seja "direito de todos e dever do Estado" e nos arts. 203 e 204 (a Assistência Social) e 205 caracteriza a educação e o ensino também como deveres do Estado, o que o impede (Estado) de desresponsabilizar-se da prestação desses serviços, restando ao setor privado o papel apenas de complementaridade. 
Por meio de estudos críticos em saúde coletiva, esboça-se que o que ocorreu, de fato com as terceirizações previstas na Lei das OSs, foi a transferência, pelo Estado, de suas unidades hospitalares, prédios, móveis, equipamentos, recursos públicos e, muitas vezes, recursos humanos para a iniciativa privada. Sob o prisma constitucional essas ações são inconstitucionais, visto que a saúde é atividade-fim do Estado e não deve ser delegada a terceiros.

Assim, a introdução da administração gerenciada, como mecanismo de gestão para o SUS, é um subterfúgio para a terceirização e a privatização de serviços do setor saúde e se transforma em problemas previsíveis, como demonstra a história da saúde no Brasil: transferência de "poupança pública" ao setor privado lucrativo; repasse de patrimônio, bens, serviços, servidores e dotação orçamentária públicos a empresas de Direito Privado; desregulamentação do Sistema Público de compra de bens e serviços (Lei 8.666/Lei das Licitações).

Com a criação das OSs e das OSCIPs, vislumbra-se a implementação da terceirização de serviços públicos como regra e o fim do Concurso Público; desorganização do processo de trabalho em saúde; flexibilização dos contratos de trabalho, precarização do trabalho; desmonte da Gestão Única do SUS; a hierarquização dos serviços de saúde fica comprometida, na medida em que cada serviço terceirizado/privatizado tem em si a característica de autonomia em relação à Administração Pública e ao SUS, como também fica comprometido o sistema de Referência e Contrarreferência (REZENDE, 2008). São por essas demonstrações que as OS e as OSCIPs comprometem o SUS.

Enfim, os vieses perversos, que implicam à saúde tal modelo de gestão, expressam, pois, o ferimento do direto à saúde. $E$, como indagamos no início acerca das modificações pertinentes à estrutura, à política e à jurisdição da saúde a fim do ideal de saúde universal, pública e estatal, percebemos concretamente a fragilidade no processo de consolidação desse direito social; ratificando, todavia, a estruturação política, jurídica, enfim, da saúde como mercadoria, como também propriedade privada.

\section{Considerações finais}

A partir do panorama histórico da saúde pré e pós-SUS, constatamos o processo da apropriação privada da saúde, desde a assistência à administração da saúde, ou seja, da 
coisa pública, dos fundos públicos, o setor privado historicamente apropria-se. Desse modo, a saúde é alvo de políticas restritivas expressas por ações como o subfinanciamento e a privatização dos serviços, bem como por meio das novas modalidades de gestão propostas para o serviço público, com as Organizações Sociais (O.S), dentre outras, refletindo a lógica neoliberal do Estado.

Esse movimento privatizante da saúde reflete outras contradições presentes no debate acerca dos Direitos Sociais, que, nos termos de Harvey (2008), significa aceitar ou submeter-se a esse conjunto de direitos necessários à acumulação do capital. Vivemos, portanto, numa sociedade em que os direitos inalienáveis dos indivíduos submetidos à propriedade privada e à taxa de lucro se sobrepõem a toda outra concepção concebível de direitos inalienáveis.

Nessa perspectiva, por tirar as máscaras do modelo econômico de nossa sociedade, "desenvolvimentista, produtivista, exploradora", a saúde pode assumir um caráter de subversiva da estrutura social.

E, quando trazemos esta discussão paralela ao modelo de desenvolvimento econômico brasileiro, observamos os limites das intervenções sobre a "questão social", na qual também a saúde agrega-se. Para os adeptos do novo-desenvolvimentismo, algumas políticas e ações sociais estariam invariavelmente associadas a mecanismos de distribuição dos recursos, de modo a enfrentar a questão da desigualdade, com foco na igualdade de oportunidades. Assim, tais iniciativas deveriam promover a redução da desigualdade com redistribuição, reconhecimento e representação, propiciando o investimento em políticas sociais e educacionais como fatores estratégicos no sentido da inclusão econômica formal de segmentos da população com baixíssimos rendimentos e para a melhoria da distribuição de renda, no sentido de minimizar as assimetrias das desigualdades causadas pela globalização do mercado (MOTA, 2010). Ou seja, a garantia da cidadania mediante o consumo da classe trabalhadora, que, todavia, não altera essencialmente a questão social do país.

Diante das considerações mencionadas, fica latente os limites que o modo de produção capitalista encerra de qualquer possibilidade de desenvolvimento, seja destinado ao humano em detrimento à acumulação do capital, seja na saúde, seja na educação. As tragédias da fome, do desemprego, conflitos ambienteis e urbanos confirmam todos os 
dias o seu esgotamento como indutor de uma sociabilidade sequer sustentável. Como bem explicita Abreu (2011), o que está em jogo é o esgotamento desse modo de produção ou a própria existência da humanidade, não em seu sentido profético, mas na dimensão das possibilidades de realização do humano. Lembrando ainda que as desigualdades sociais são geradas pelo capitalismo, e não pela sua ausência; como tentam sugerir os defensores do neodesenvolvimentismo.

\section{Referências}

ABREU, M. H. O viés do (neo) desenvolvimentismo no debate sobre a categoria território no serviço social. In: CIRCUITO DE DEBATES ACADÊMICOS, 1., 2011, Brasília. Anais... Brasília, 2011. p. 1-20.

BAHIA, L. A. Démarche do privado e público no sistema de atenção à saúde no Brasil em tempos de democracia e ajuste fiscal, 1988-2008. In: MATTA, G. (Org.). Estado, sociedade e formação profissional em saúde: contradições e desafios em 20 anos de SUS. Rio de Janeiro: Fiocruz/EPSJV, 2008.

BIELSCHOWSKY, R. Pensamento econômico brasileiro: o ciclo ideológico do desenvolvimentismo. Rio de Janeiro: IPEA, 1988.

BORON, A. Duro de matar. el mito del desarrollo capitalista nacional . In: ENCUENTRO INTERNACIONAL DE ECONOMISTAS SOBRE GLOBALIZACIÓN Y PROBLEMAS DEL DESARROLLO, 9., 2007, La Habana. Anales... La Habana: ANEC, 2007.

BRAGA, J. C. S.; PAULA, S. G. Saúde e previdência: estudos de política social. São Paulo: Cebes-Hucitec, 1981.

BRASIL. Constituição (1988). Constituição da República Federativa do Brasil. Senado Federal: Centro Gráfico, Brasília, 1988.

Lei no 9.637, de 15 de maio de 1998. Dispõe sobre a qualificação de entidades como organizações sociais, a criação do Programa Nacional de Publicização, a extinção dos órgãos e entidades que menciona e a absorção de suas atividades por organizações sociais, e dá outras providências. Diário Oficial da União, Brasília, 24 abr.1998.

BRAVO, M. et al. Política de saúde na atual conjuntura: modelos de gestão e agenda para a saúde. 2. ed. Rio de Janeiro: Rede Sirius, 2008.

BRESSER-PEREIRA, L. O novo desenvolvimentismo e a ortodoxia convencional. São Paulo em perspectiva, São Paulo, v. 20, n. 3, p. 5-24, jul./set. 2006.

FONTES, V. O Brasil e o capital-imperialismo. Rio de Janeiro: EPSJV/UFRJ, 2010. 
GERSCHMAN, S. Políticas comparadas de saúde suplementar no contexto de sistemas públicos de saúde: União Europeia e Brasil. Ciência saúde coletiva, Rio de Janeiro, v. 13, n. 5, 2008.

HARVEY, D. Condição pós-moderna. 12. ed. São Paulo: Loyola, 2003.

MOTA, A. (Org.). As ideologias da contrarreforma e o serviço social. Recife: UFPE, 2010.

PAULO NETTO, J. Capitalismo monopolista e serviço social. São Paulo: Cortez, 1992.

OLIVEIRA, F. Os direitos do antivalor: a economia política da hegemonia imperfeita. Petrópolis: Vozes, 1998.

PAIM, J. Reforma sanitária brasileira: contribuição para a compreensão e crítica. Salvador: EDUFBA, 2007.

REZENDE, C. O Modelo de gestão do SUS e as ameaças do projeto neoliberal. In: BRAVO, M. et al. (Org.). Política de saúde na atual conjuntura: modelos de gestão e agenda para a saúde. 2. ed. Rio de Janeiro: Rede Sirius, 2008.

SANTOS, I. O mix público-privado no sistema de saúde brasileiro: elementos para a regulação da cobertura duplicada. 2009. Tese (Doutorado em ciências na área de saúde pública) - Escola Nacional de Saúde Pública Sergio Arouca, FIOCRUZ, Rio de Janeiro, 2009.

SANTOS, R. Crescimento econômico e equidade social: o modelo novo-desenvolvimentista de intervenção sobre a "questão social". In: JORNADA INTERNACIONAL DE POLÍTICAS PÚBLICAS, 3., 2007, São Luís. Jornada... São Luís, 2007. p. 1-8.

SANTOS, R. O social-liberalismo: a ideologia neoliberal para a "questão social" no século XXI. 2011. Tese (Doutorado em serviço social) - Universidade Federal do Rio de Janeiro, Rio de Janeiro, 2011.

SISCÚ, J.; PAULA, L. F.; MICHEL, R. Por que novo-desenvolvimentismo? Revista de Economia Política, São Paulo, v. 27, n. 4, 2007.

SKIDELSKY, R. Keynes. Rio de Janeiro: Jorge Zahar, 1999. 